University of Nebraska - Lincoln

DigitalCommons@University of Nebraska - Lincoln

USDA National Wildlife Research Center - Staff Publications
U.S. Department of Agriculture: Animal and Plant Health Inspection Service

May 2006

\title{
Impact on predation of sea turtle nests when predator control was removed midway through the nesting season
}

\author{
Richard M. Engeman \\ USDA-APHIS-Wildlife Services, s_r100@yahoo.com \\ R. Erik Martin \\ Ecological Associates, Inc. \\ Henry T. Smith \\ Florida Department of Environmental Protection, Florida Park Service \\ John Woolard \\ USDA/APHIS/Wildlife Services \\ Carrie K. Crady \\ Ecological Associates, Inc.
}

See next page for additional authors

Follow this and additional works at: https://digitalcommons.unl.edu/icwdm_usdanwrc

Part of the Environmental Sciences Commons

Engeman, Richard M.; Martin, R. Erik; Smith, Henry T.; Woolard, John; Crady, Carrie K.; Constantin, Bernice ; Stahl, Margo; and Groninger, N. Paige, "Impact on predation of sea turtle nests when predator control was removed midway through the nesting season" (2006). USDA National Wildlife Research Center - Staff Publications. 417.

https://digitalcommons.unl.edu/icwdm_usdanwrc/417

This Article is brought to you for free and open access by the U.S. Department of Agriculture: Animal and Plant Health Inspection Service at DigitalCommons@University of Nebraska - Lincoln. It has been accepted for inclusion in USDA National Wildlife Research Center - Staff Publications by an authorized administrator of DigitalCommons@University of Nebraska - Lincoln. 


\section{Authors}

Richard M. Engeman, R. Erik Martin, Henry T. Smith, John Woolard, Carrie K. Crady, Bernice Constantin, Margo Stahl, and N. Paige Groninger 


\title{
Impact on predation of sea turtle nests when predator control was removed midway through the nesting season
}

\author{
Richard M. Engeman ${ }^{\mathrm{A}, \mathrm{F}}$, R. Erik Martin ${ }^{\mathrm{B}}$, Henry T. Smith ${ }^{\mathrm{C}}$, John Woolard ${ }^{\mathrm{D}}$, Carrie K. Crady ${ }^{\mathrm{B}}$, \\ Bernice Constantin ${ }^{\mathrm{D}}$, Margo Stahl ${ }^{\mathrm{E}}$ and N. Paige Groninger ${ }^{\mathrm{A}}$

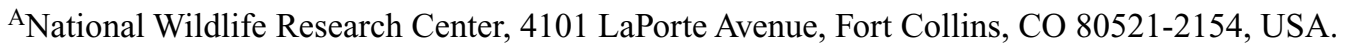 \\ ${ }^{B}$ Ecological Associates, Inc., PO Box 405, Jensen Beach, FL 34958, USA. \\ ${ }^{\mathrm{C}}$ Florida Department of Environmental Protection, Florida Park Service, \\ 13798 S.E. Federal Highway, Hobe Sound, FL 33455, USA. \\ DUSDA/APHIS/Wildlife Services, 2820 East University Avenue, Gainesville, FL 32641, USA. \\ ${ }^{E}$ Hobe Sound National Wildlife Refuge, 13640 S.E. Federal Highway, Hobe Sound, FL 33455, USA. \\ ${ }^{\mathrm{F} C o r r e s p o n d i n g ~ a u t h o r . ~ E m a i l: ~ r i c h a r d . m . e n g e m a n @ a p h i s . u s d a . g o v ~}$
}

\begin{abstract}
The beach at Hobe Sound National Wildlife Refuge (HSNWR) is a high-density nesting beach serving three species of threatened and endangered sea turtles. Historically, up to $95 \%$ of turtle nests at HSNWR were lost to predation by raccoons and armadillos. Consequently, predator control was identified as the most important conservation tool at HSNWR, and predator control optimised by predator monitoring led to highly successful results whereby predation had been reduced to low levels (7-13.5\% of monitored nests) in 2002 and 2003. In 2004, funding shortfalls caused predator control to be curtailed with $\sim 1.5-2$ months remaining in the nesting/hatching season. We analysed the resulting effects on turtle nest predation levels compared with the results from 2002 and 2003 . The predation rate in 2004 compared favourably with that of 2002 and 2003 until the end of June, after which control was curtailed. Thereafter, predation rapidly accelerated, with the 2004 predation rate increasing to $1.5-3$ times the rates from 2002 and 2003 by the end of August. The discrepancy in all likelihood would have grown further, except Hurricane Frances destroyed all remaining nests with 1.5-2 months left in the nesting/hatching season. Product-limit survival analyses demonstrated substantial differences in turtle nest survival between 2004 versus 2002 and 2003, but not between 2002 and 2003. When analysed as cohorts based on month of nest deposition, no differences were found among 2002, 2003, 2004 for nests deposited in May. These nests received full protection from predation in each of the three years. However, the survival analyses for nests deposited in June, and those deposited in July showed inferior survival for 2004 when predator control was removed for the last half of nesting/hatching.
\end{abstract}

\section{Introduction}

Sea turtle nesting beaches in Florida have been substantially altered by urbanisation and development, leaving few beaches isolated from development. Raccoons (Procyon lotor) are an abundant native species that impact sea turtle conservation at many Florida beaches through nest depredation (Stancyk 1982; Williams-Walls et al. 1983; Mroziak et al. 2000; Garmestani and Percival 2005). Compounding the problem, raccoon populations flourish in association with humans because they often receive artificial support through refuse or direct feeding (Dickman and Doncaster 1987; Riley et al. 1998; Smith and Engeman 2002). Besides conservation problems posed by abundant native wildlife, Florida has one of the two most severe invasive species problems in the United States (US Congress 1993). Armadillos (Dasypus novemcinctus) are invasive to Florida (Schmitz and Brown 1994) and also are primary excavators and predators of sea turtle nests, causing severe damage (Drennen et al. 1989;
Bain et al. 1997). Beyond direct predation, these primary nest excavators also expose nests to the elements and to predation by crabs, birds, and other mammals.

Predation critically threatens many rare species (Hecht and Nickerson 1999), with the deleterious impacts of predation losses compounded by habitat loss (Reynolds and Tapper 1996). Both problems apply to sea turtle nesting at many Florida beaches, making human intervention necessary to ensure turtle reproduction. Reduction of nest predator populations has been widely recommended (Bain et al. 1997; Mroziak et al. 2000), and widely practiced, to protect sea turtle nests (Stancyk 1982; US Fish and Wildlife Service and National Marine Fisheries Service 1991; US Fish and Wildlife Service 2000; Engeman et al. 2003, 2005; Garmestani and Percival 2005).

Hobe Sound National Wildlife Refuge (HSNWR) on Jupiter Island along Florida's east coast provides undeveloped and protected beach habitat for nesting by loggerhead 
(Caretta caretta), leatherback (Dermochelys coriacea) and green (Chelonia mydas) turtles, each of which is federally listed as threatened or endangered (US Fish and Wildlife Service 1994), and classified on the IUCN Red list as endangered (loggerhead and green turtles) or critically endangered (leatherback turtles) (IUCN 2004). Raccoons and armadillos are serious nest predators at HSNWR (US Fish and Wildlife Service 2000), and minor additional predation by bobcats (Felis rufus), opossums (Didelphis virginiana) and spotted skunks (Spilogale putorius) also takes place (Woolard et al. 2004; Martin et al. 2005). Prior to managing predators, up to 95\% of turtle nests were depredated each year at HSNWR (Bain et al. 1997). Consequently, predator removal was identified as the most important management program at the beach (Bain et al. 1997; US Fish and Wildlife Service 2000). A highly successful approach for predator control has been applied to the HSNWR beach since 2000, whereby the control efforts are optimised using information on timing and location of predation gained from passive tracking index methodology (Engeman et al. 2003, 2005). Using this approach, predation was reduced to less than $10 \%$ by 2002 (Engeman et al. 2005). Unfortunately, in 2004 a funding shortfall caused control to be curtailed, and then halted, in the midst of the turtle nesting/hatching season. The aim of the present study is to evaluate the impact on nest predation resulting from removal of predator control midway through the nesting season.

\section{Study area and methods}

Turtle nesting beach

The beach is located on the northern portion of Jupiter Island, a narrow, 27-km-long barrier island. Hobe Sound National Wildlife Refuge (HSNWR) occupies 298 ha and protects a $5.3-\mathrm{km}$ segment of beach, which varies in slope and width, but has a well defined dune line. The HSNWR beach is open to the public during daylight hours, but is accessible only by boat or by foot from its southern boundary. The nesting aggregation at HSNWR is in the centre of loggerhead nesting activity in the USA, which is the second largest loggerhead nesting concentration in the world and is crucial to the survival of loggerhead turtles globally (Meylan et al. 1995).

\section{Predator-removal methods}

A comprehensive environmental assessment identified lethal predator removal as the only practical and legal approach for reducing nest predation (US Fish and Wildlife Service 2000). The predator species are largely nocturnal and removal efforts were conducted at night (during property closure), which also minimised the potential for human interference. Approximately half of the raccoons were captured in live traps and killed. The rest of the raccoons and all armadillos were removed from the beach using a 0.22 calibre rifle equipped with a noise suppressor and night-vision equipment to maximise hunting success while minimising disturbance. Predator control was carried out by the US Department of Agriculture/Wildlife Services, the federal agency responsible for managing conflicts with wildlife (US Department of Agriculture/Animal and Plant Health Inspection Service et al. 1997). Wildlife Services uses only approved and humane methods to kill animals, which conform to the guidelines laid out in the 2000 Report of the American Veterinary Medical Association Panel on Euthanasia
(American Veterinary Medical Association 2001) and set forth as agency policy in USDA/APHIS/WS Directive 2.505. The applied control approaches had been specifically identified as appropriate for HSNWR (US Fish and Wildlife Service 2000).

The timing and location of removal efforts were determined by predator monitoring and observed predation. Since 2000, predator removal has incorporated a passive tracking methodology to optimise the timing, location and assessment of control activities (Engeman et al. 2003, 2005). In this approach, predators are monitored and indexed using tracking plots spaced approximately every $200 \mathrm{~m}$ along the beach (see Engeman 2005 for general indexing methodology). The resulting data are used to time and focus control activities, and to assess control efficacy. The methodology evolved to the point that, by 2002, predation was reduced to under 10\% (Engeman et al. 2005) and, in 2003, the predation rate remained low at $<14 \%$ (Ecological Associates 2004). Optimised predator removal continued in 2004. However, a lack of funding resulted in removal of control during the last two weeks of June, resumption in July, and complete discontinuation on 5 August 2004.

\section{Monitoring nesting activity of turtles}

The beach was monitored daily for nest deposition beginning in March, with all sea turtle nests counted the morning after deposition. All green and leatherback turtle nests were marked for monitoring reproductive success. Nearly $90 \%$ of the $950-1850$ nests deposited annually are by loggerhead turtles. The large number of loggerhead nests allowed us to mark only every eighth loggerhead turtle nest for monitoring. Beginning with the first day of deposition, every eighth loggerhead turtle nest observed sequentially along the beach was marked, with the sequence continuing the following day from where it left off the day before. After physical location of the nest by careful excavation, a $120-\mathrm{cm}$-long stake placed on the north-south axis $60 \mathrm{~cm}$ from the clutch, and two $60-\mathrm{cm}$-long stakes placed $60 \mathrm{~cm}$ east and west of the clutch were labelled with observation date, location and turtle species, and joined by surveyor's tape. The redundancy of identifying stakes on precise compass axes at a precise $60-\mathrm{cm}$ distance from the clutch made nest relocation easy and accurate, even if one or two marking stakes were lost (a very rare occurrence). Marked nests were monitored daily for depredation, hatchling emergence, tidal overwash, erosion, or other disturbance. Three days after the first observed hatchling emergence, marked nests were excavated to determine reproductive success. Nests showing no signs of hatchling emergence were excavated after 70 days for loggerhead and green turtles, and 80 days for leatherback turtles. The numbers of hatched eggs, unhatched eggs, live and dead hatchlings, and live and dead embryos in pipped eggs were recorded. All live hatchlings were handled and released in accordance with Florida's Sea Turtle Conservation Guidelines (Florida Fish and Wildlife Conservation Commission 2002). On 5 September 2004 Hurricane Frances struck the beach, with the storm surge eroding much of the beach and destroying all sea turtle nests remaining there.

\section{Data analyses}

The ultimate measure of annual predation is the final percentage of marked nests that had been lost to predation, and is typically used as the benchmark criterion for assessing success at protecting nests. The cumulative predation to any given time within a nesting season yields the status of predation's effects to that point. It should be noted that the cumulative percentage predation can decrease within a nesting season, if nest deposition outpaces the existing predation rate. Once nest deposition has stopped, the nests remaining in the beach are still vulnerable to predation. Consequently, predation rates have little option but to go up or stay the same thereafter. An ideal analytical design would match this beach with a similar beach nearby that received predator control throughout the nesting season. Unfortunately, such a matched pair does not exist and predation rates had to be compared before and after 
removal of control in 2004, and to results from previous years on the same beach.

Detailed comparisons of predation among the years 2002, 2003 and 2004 were accomplished by a non-parametric analysis of the time in days until nests were depredated using product-limit survival analyses (Kaplan and Meier 1958). Wilcoxon comparisons of survival curves (Kalbfleish and Prentice 1980) were applied to compare rates between 2004 (when control was removed) to 2002 and 2003 (when control was applied throughout the season). Nests hatching or destroyed by causes other than predation were considered censored at the time of the event (i.e. the fate of a censored nest relative to predation could not be determined owing to its loss by other means, the censoring event). The analyses allowed for the use of survival times from censored observations up until the censoring event. Hurricane Frances struck on 5 September 2004 , at which point all nests in the sand were destroyed and nest survival times were censored at that point. To make 2002 and 2003 comparable with 2004, survival times in days for nests in those years were also censored at 5 September. Analyses were carried out using SAS PROC LIFETEST (SAS Institute 2004).

Nest survival analyses were carried out in two ways. In the first, all nest data within each year were treated as a single cohort for a general comparison among the years 2002-04. The second approach was to compare survival curves among 2002, 2003 and 2004 in separate analyses for nests deposited within May, June and July. Nests deposited in August of 2004 were incubated for only 5-35 days prior to being destroyed by Hurricane Frances (at most only $50 \%$ of their incubation period). Thus, all non-depredated nests would have their survival times censored early in the incubation period. This limited exposure for August nests to the possibility of predation made survival comparisons with the previous two years ineffectual. Nests take roughly two months to hatch. Therefore nests deposited in May received the full benefit of predator control in all three years. In theory, differences in predation impacts would first be evident for nests deposited in June because, on average, the June 2004 nests received protection for only half of their incubation period. Nests deposited in July 2004 would have been largely unprotected after deposition, and therefore also would be expected to show differences in survival from the previous two years. Many of the July nests had their survival times censored by the hurricane, making detection of differences in survival less sensitive than for May or June nests.

\section{Results}

Cumulative predation over a nesting season was known exactly for green and leatherback turtles because all nests were monitored. The number of depredated loggerhead turtle nests was estimated by applying predation rates from the random sample of monitored nests to the (known) total number of loggerhead turtle nests deposited. Thus, combined cumulative predation across all turtle species can be calculated as just the depredated proportion of the combined monitored nests, or by adjusting for the number of nests deposited by each species. In that case the estimated number of depredated loggerhead turtle nests is added to the (known) depredated number of green and leatherback turtle nests and divided by the total number of nests on the beach. The predation rates from the two calculation methods were usually similar (Table 1), although for the 2002 data the combined predation using only monitored nests was $9.4 \%$, but adjustment for the numbers of nests by each species resulted in an estimate of $6.9 \%$ as the combined final predation rate (Table 1).

Table 1. Cumulative deposition of nests and associated predation rates by the end of the months May-September for three species of sea turtle at Hobe Sound National Wildlife Refuge, Florida, USA

All green and leatherback turtle nests and one in eight loggerhead turtle nests were monitored for fate. Predation on all species combined was calculated two ways (final two columns): just the depredated proportion of only monitored nests, and adjusting for the number of nests deposited by each species. No data are shown for September 2004, because Hurricane Frances destroyed all remaining nests on 5 September. August predation levels are highlighted for ease of comparison among years. $\mathrm{nn}=$ no nests, therefore calculation of a predation rate is inappropriate

\begin{tabular}{|c|c|c|c|c|c|c|c|c|c|}
\hline \multirow[t]{2}{*}{ Year and month } & \multicolumn{2}{|c|}{ Loggerhead } & \multicolumn{2}{|c|}{ Green } & \multicolumn{2}{|c|}{ Leatherback } & \multicolumn{3}{|c|}{ All Species } \\
\hline & $\begin{array}{l}\text { Cumulative } \\
\text { no. of } \\
\text { nests }\end{array}$ & $\begin{array}{c}\% \text { Pred } \\
\text { monitored } \\
\text { nests }\end{array}$ & $\begin{array}{c}\text { Cumulative } \\
\text { no. of } \\
\text { nests }\end{array}$ & $\begin{array}{c}\% \text { Pred } \\
\text { monitored } \\
\text { nests }\end{array}$ & $\begin{array}{c}\text { Cumulative } \\
\text { no. of } \\
\text { nests }\end{array}$ & $\begin{array}{c}\% \text { Pred } \\
\text { monitored } \\
\text { nests }\end{array}$ & $\begin{array}{c}\text { Cumulative } \\
\text { no. of } \\
\text { nests }\end{array}$ & $\begin{array}{c}\% \text { Pred } \\
\text { monitored } \\
\text { nests }\end{array}$ & $\begin{array}{c}\text { Adj } \% \\
\text { pred }\end{array}$ \\
\hline \multicolumn{10}{|l|}{2002} \\
\hline May & 329 & 0.0 & 2 & 0.0 & 28 & 0.0 & 359 & 0.0 & 0.0 \\
\hline June & 730 & 0.0 & 48 & 0.0 & 32 & 0.0 & 810 & 0.0 & 0.0 \\
\hline July & 1016 & 3.9 & 111 & 0.9 & 33 & 0.0 & 1160 & 2.2 & 3.5 \\
\hline August & 1062 & 6.1 & 138 & 10.1 & 33 & 0.0 & 1233 & 7.3 & 6.3 \\
\hline September & 1062 & 6.1 & 143 & 14.7 & 33 & 0.0 & 1238 & 9.4 & 6.9 \\
\hline \multicolumn{10}{|l|}{2003} \\
\hline May & 303 & 2.7 & 0 & $\mathrm{nn}$ & 38 & 0.0 & 391 & 1.4 & 2.0 \\
\hline June & 898 & 6.3 & 7 & 0.0 & 47 & 4.3 & 952 & 5.5 & 6.1 \\
\hline July & 1313 & 7.3 & 38 & 0.0 & 48 & 6.4 & 1399 & 6.0 & 7.1 \\
\hline August & 1427 & 11.8 & 67 & 10.4 & 48 & 6.4 & 1542 & 10.6 & 11.6 \\
\hline September & 1427 & 13.5 & 73 & 19.2 & 48 & 6.4 & 1548 & 13.8 & 13.5 \\
\hline \multicolumn{10}{|l|}{2004} \\
\hline May & 161 & 0.0 & 0 & $\mathrm{nn}$ & 28 & 0.0 & 189 & 0.0 & 0.0 \\
\hline June & 525 & 4.6 & 4 & 0.0 & 34 & 5.9 & 563 & 4.9 & 4.6 \\
\hline July & 918 & 13.2 & 48 & 10.4 & 35 & 5.9 & 1001 & 11.2 & 12.8 \\
\hline August & 988 & 24.4 & 97 & 19.6 & 35 & 8.6 & 1120 & 20.4 & 23.5 \\
\hline
\end{tabular}


The cumulative predation rate through June 2004 compared favourably with the results for 2002 and 2003 in the same period. However, by the end of July 2004 (after control had been removed for the final two weeks in June) predation was beginning to outpace that of the previous two years and, by the end of August 2004, predation was over $20 \%$ (Table 1),
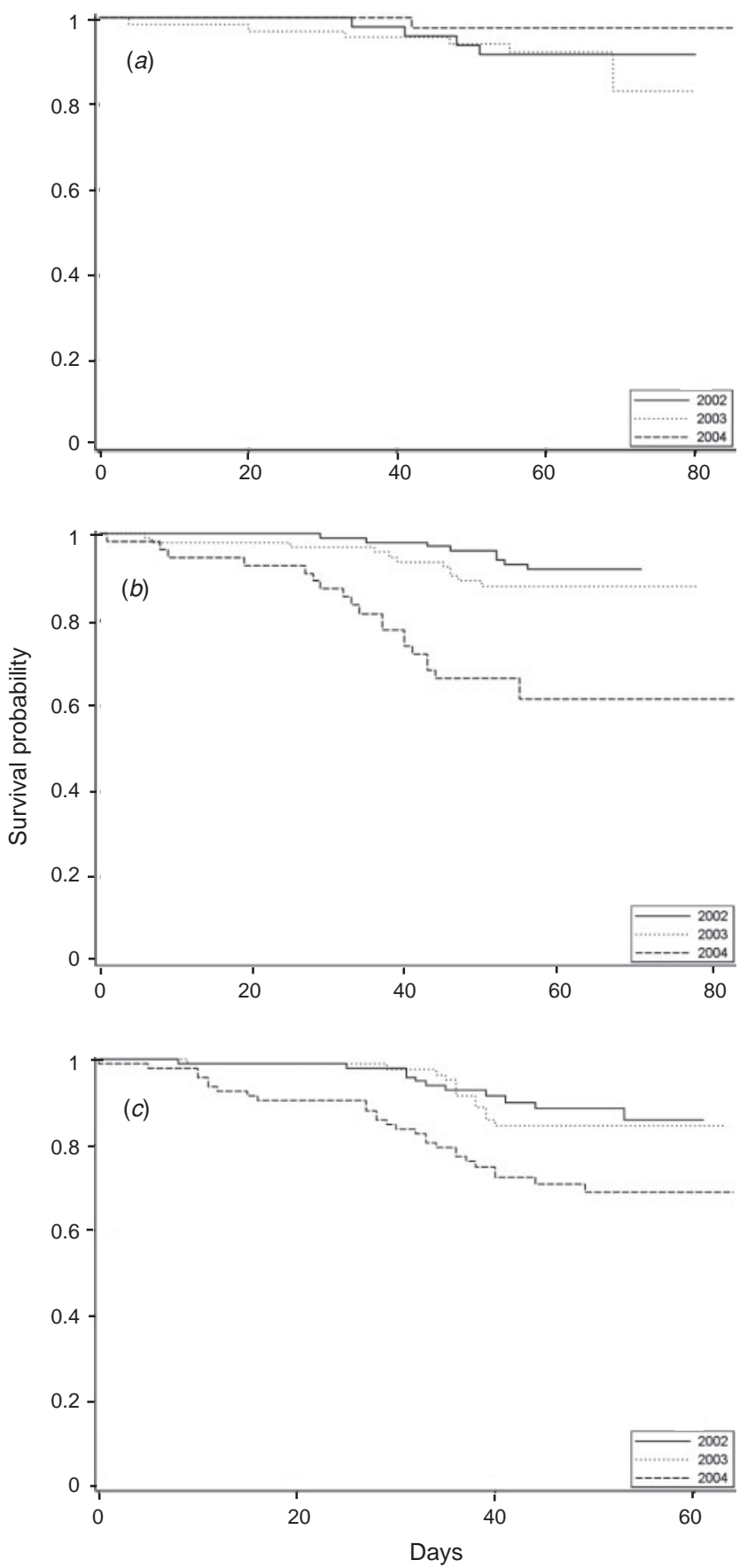

Fig. 1. Comparative survival curves for sea turtle nests among the years 2002, 2003, 2004 for nests deposited in (a) May, (b) June and (c) July. Nests that hatched or were lost to causes other than predation were censored at the time of the event. or twice the adjusted rate for the same period in 2003 and over three times that in 2002. The predation rate at the end of August also was over twice the final predation rate for all of 2002 and 1.5 times the final predation rate for all of 2003, even though those final predation rates included a minimum of one extra month of potential exposure to predation.

The 2004 curve for nest survival times differed strongly from the 2003 survival curve $\left(\chi^{2}=17.8\right.$, d.f. $\left.=1, P<0.0001\right)$ and the 2002 survival curve $\left(\chi^{2}=29.6\right.$, d.f. $\left.=1, P<0.0001\right)$. The nest survival curves for the two years where predator control was maintained through nesting and hatching (2002, 2003) did not differ $\left(\chi^{2}=1.50\right.$, d.f. $\left.=1, P=0.22\right)$.

The comparisons of nest survival among 2002, 2003 and 2004 based on month of deposition reflected expectations based on consistency of predator control applied during their incubation periods. No differences in survival were detected among the years for nests deposited in May (in each case $\chi^{2}<1.56$, d.f. $=1, P>0.21$ ) (Fig. 1a). However, nests deposited in June 2002 and June 2003 each showed greater survival times than the nests deposited in June 2004 (respectively, $\chi^{2}=23.9$, d.f. $=1, P<0.0001$ and $\chi^{2}=11.8$, d.f. $=1$, $P=0.0006$ ) (Fig. 1b), but no difference from each other $\left(\chi^{2}=1.66\right.$, d.f. $\left.=1, P=0.20\right)$ (Fig. $\left.1 b\right)$. Similar results held for nests deposited in July, with those from 2002 and 2003 showing strong differences from those in 2004 (respectively, $\chi^{2}=10.6$, d.f. $=1, P<0.0011$ and $\chi^{2}=6.55$, d.f. $=1$, $P=0.0105$ ) (Fig. 1c), but not from each other $\left(\chi^{2}=0.37\right.$, d.f. $=1, P=0.54$ ) (Fig. $1 c$ ). The lesser $P$-values for July reflect that nests deposited later in July 2004 were not vulnerable to predation for a substantial portion of the incubation period because of the hurricane.

\section{Discussion}

Raccoons respond almost immediately to the onset of heavy turtle nesting (Engeman et al. 2003, 2005), whereas armadillos tend to add to predation after about a month of nesting (Engeman et al. 2003). Evidence suggests that raccoon migrations to nesting beaches may be cultural (passed on from one generation to the next) because on some beaches most raccoon predation occurs on the night of egg deposition (Anderson 1981) whereas predation rarely occurs then on other beaches (Ehrhart and Witherington 1986; Engeman et al. 2003). Animals also would be expected to become more proficient nest predators through the course of the nesting season. Without predator removal, predation pressures would escalate through a nesting season.

Since control was stopped with $\sim 1.5-2$ months of hatching remaining in 2004, but at a time of decreasing nesting, the cumulative predation rate in all likelihood would have continued to increase had Hurricane Frances not wiped out all nests. Even so, predation through only three-quarters of the 2004 nesting/hatching season substantially outpaced predation for the entire season in the two preceding years. The importance of the nests lost to predation was heightened by 
the complete destruction of all remaining nests with considerable hatching left in the season. Indications are that the excess loss to predation relative to the previous two years may have been avoidable if predator control could have been maintained through the nesting/hatching season.

There has been speculation that removal of animals highly experienced and skilled at detection and excavation of turtle nests would help reduce predation in future years by breaking a cultural cycle whereby this knowledge would not be passed from one generation to the next (Engeman et al. 2003). Application of approximately the same control effort and methods from 2000 through 2003 resulted in dramatic reductions in predation to where a $10 \%$ predation rate at HSNWR could be expected, rather than imagined (Engeman et al. 2005). It is possible that impeding a cultural transfer of knowledge contributed to this success, but the 2004 results are also significant in their demonstration that the absence of predator control invites a response of rapidly escalating nest predation, whether or not a cultural learning cycle had been broken.

Predator removal has been well recognised as the most valuable management option for maximising sea turtle reproduction at HSNWR (Bain et al. 1997; US Fish and Wildlife Service 2000). An important lesson to take away from the results for the 2004 nesting season is that outstanding reductions in nest predation for multiple consecutive years do not carry forward to the future without application of the same methods that produced the success. Clearly, the control that in prior years produced exemplarily low predation, and another half-season of similarly low predation did not assure low predation in the absence of control in even the second half of a nesting season.

Unfortunately, unforeseen budgetary or logistical issues can loom at anytime. In such circumstances, economic analyses can greatly assist managers on how most efficiently and effectively to allocate limited funds towards species conservation (Engeman et al. 2004). Engeman et al. (2002), using a conservative valuation for hatchling turtles, demonstrated that returns on a control investment of less than $\$ 10000$ ranged in the millions of dollars worth of hatchling turtles. Therefore, in terms of prioritising expenditures during lean budget years, maintaining an active predator-control program would probably represent among the most economically, as well as biologically, rewarding allocations of management funds. On beaches with a history of high losses of turtle nests to predators every effort should be made to ensure that predators are managed through the entire nesting/hatching season. It is one of the most cost-effective management tools available for maximising the number of hatchlings produced.

\section{References}

American Veterinary Medical Association (2001). 2000 report of the AVMA panel on euthanasia. Journal of the American Veterinary Medical Association 218, 669-696. doi:10.2460/javma.2001. 218.669
Anderson, S. (1981). The raccoon (Procyon lotor) on St Catherines Island, Georgia. 7. Nesting sea turtles and foraging raccoons. American Museum Novitates 2713, 1-9.

Bain, R. E., Jewell, S. D., Schwagerl, J., and Neely, B. S., Jr (1997). Sea turtle nesting and reproductive success at the Hobe Sound National Wildlife Refuge (Florida), 1972-1995. Report to US Fish and Wildlife Service, ARM Loxahatchee NWR.

Dickman, C. R., and Doncaster, C. P. (1987). The ecology of small mammals in urban habitats. I. Populations in a patchy environments. Journal of Animal Ecology 56, 629-640.

Drennen, D., Cooley, D., and Devore, J. E. (1989). Armadillo predation on loggerhead turtle eggs at two national wildlife refuges in Florida, USA. Marine Turtle Newsletter 1989, 7-8.

Ecological Associates. (2004). Hobe Sound National Wildlife Refuge, Jupiter Island Florida. Results of 2003 Sea Turtle Monitoring. Report to US Fish and Wildlife Service, ARM Loxahatchee NWR.

Engeman, R. M. (2005). A methodological and analytical paradigm for indexing animal populations applicable to many species and observation methods. Wildlife Research 32, 203-210. doi:10.1071/ WR03120

Engeman, R. M., Shwiff, S. A., Constantin, B., Stahl, M., and Smith, H. T. (2002). An economic analysis of predator removal approaches for protecting marine turtle nests at Hobe Sound National Wildlife Refuge. Ecological Economics 42, 469-478. doi:10.1016/S0921-8009(02)00136-2

Engeman, R. M., Martin, R. E., Constantin, B., Noel, R., and Woolard, J. (2003). Monitoring predators to optimize their management for marine turtle nest protection. Biological Conservation 113, 171-178. doi:10.1016/S0006-3207(02)00295-1

Engeman, R. M., Shwiff, S. A., Smith, H. T., and Constantin, B. U. (2004). Monetary valuation of rare species and imperiled habitats as a basis for economically evaluating conservation approaches. Endangered Species Update 21, 66-73.

Engeman, R. M., Martin, R. E., Smith, H. T., Woolard, J., Crady, C. K., Shwiff, S. A., Constantin, B., Stahl, M., and Griner, J. (2005). Dramatic reduction in predation on sea turtle nests through improved predator monitoring and management. Oryx 39, 318-326. doi: $10.1017 / \mathrm{S} 0030605305000876$

Ehrhart, L. M., and Witherington, B. E. (1986). Human and natural causes of marine turtle nest and hatchling mortality and their relationship to hatchling production on an important Florida nesting beach. Report to Florida Game and Fresh Water Commission, Tallahassee, FL.

Florida Fish and Wildlife Conservation Commission (2002). Sea Turtle Conservation Guidelines. Florida Fish and Wildlife Conservation Commission, Tallahassee, FL.

Garmestani, A. S., and Percival, H. F. (2005). Raccoon removal reduces sea turtle nest predation in the Ten Thousand Islands of Florida. Southeastern Naturalist 4, 469-472.

Hecht, A., and Nickerson, P. R. (1999). The need for predator management in conservation of some vulnerable species. Endangered Species Update 16, 114-118.

IUCN (2004). '2003 IUCN Red List of Threatened Species.' www.redlist.org.

Kalbfleish, J. D., and Prentice, R. L. (1980). 'The Statistical Analysis of Failure Time Data.' (John Wiley and Sons: New York.)

Kaplan, E. L., and Meier, P. (1958). Nonparametric estimation from incomplete observations. Journal of the American Statistical Association 53, 457-481.

Martin, R. E., Engeman, R. M., Smith, H. T., Stahl, M., and Constantin, B. (2005). Cheloniidae (marine turtle) bobcat nest predation. SSAR Herpetological Review 36, 56-57.

Meylan, A., Schroeder, B., and Mosier, A. (1995). 'Sea Turtle Nesting Activity in the State of Florida 1979-1992.' Florida Marine Research Publication No. 52. (Florida Marine Research Institute: St Petersburg, FL.) 
Mroziak, M. L., Salmon, M., and Rusenko, K. (2000). Do wire cages protect sea turtles from foot traffic and nest predators? Chelonian Conservation and Biology 3, 693-698.

Reynolds, J. C., and Tapper, S. C. (1996). Control of mammalian predators in game management and conservation. Mammal Review 26, $127-156$

Riley, S. P. D., Hadidian, J., and Manski, D. A. (1998). Population density, survival, and rabies in raccoons in an urban national park. Canadian Journal of Zoology 76, 1153-1164. doi:10.1139/cjz-766-1153

SAS Institute (2004). 'SAS/STAT User's Guide. Vol. 3.' (SAS Institute: Carey, NC.)

Schmitz, D. C., and Brown, T. C. (1994). An assessment of invasive non-indigenous species in Florida's public lands. Florida Department of Environmental Protection, Tallahassee, FL.

Smith, H. T., and Engeman, R. M. (2002). An extraordinary raccoon density at an urban park in Florida. Canadian Field Naturalist 116 , 636-639.

Stancyk, S. E. (1982). Non-human predators of sea turtles and their control. In 'Biology and Conservation of Sea Turtles'. (Ed. K. A. Bjorndal.) pp. 139-152. (Smithsonian Institution Press: Washington, DC.)

US Congress (1993). 'Harmful Non-indigenous Species in the United States.' (Office of Technology Assessment, OTA-F-565, Government Printing Office: Washington, DC.)
US Department of Agriculture/Animal and Plant Health Inspection Service, US Department of Agriculture/Forest Service and Department of Interior/Bureau of Land Management. (1997). Animal Damage Control Program Final Environmental Impact Statement (Revised). USDA/Animal and Plant Health Inspection Service, Washington, DC.

US Fish and Wildlife Service (1994). Endangered and threatened wildlife and plants. Federal Register 50, 17.11-17.12.

US Fish and Wildlife Service (2000). Environmental assessment for the management of predation losses to sea turtle nests at the Hobe Sound National Wildlife Refuge, Martin County, Florida. US Fish and Wildlife Service, Hobe Sound, FL.

US Fish and Wildlife Service, National Marine Fisheries Service (1991). Recovery plan for US population of loggerhead turtle. National Marine Fisheries Service: Washington, DC.

Williams-Walls, N. J., O'Hara, J., Gallagher, R. M., Worth, D. F., Peery, B. D., and Wilcox, J. R. (1983). Spatial and temporal trends of sea turtle nesting on Hutchinson Island, Florida, 1971-1979. Bulletin of Marine Science 33, 55-66.

Woolard, J., Engeman, R. M., Smith, H. T., and Griner, J. (2004). Cheloniidae (marine turtle) nest predation. SSAR Herpetological Review 35, 379-380.

Manuscript received 12 May 2005, accepted 17 March 2006 